\title{
ENHANCEMENT OF STUDENTS LEARNING OUTCOME BY SUPPLEMENTING SELF-DIRECTED LEARNING WITH VIDEO CLIPPING.
}

1. MBBS, M.Phil

Assistant Professor Physiology

Mekran Medical College, Turbat.

2. MBBS, M.Phil, Ph.D

Professor of Physiology

Islamic International Medical

College, Rawalpindi.

Correspondence Address:

Dr. Noman Sadiq

House No.180, Beella Road,

Sector G-10/1, Islamabad.

noman_sadiq89@yahoo.com

Article received on:

30/04/2019

Accepted for publication:

$11 / 10 / 2019$

\begin{abstract}
Noman Sadiq ${ }^{1}$, Shazia Ali $^{2}$
ABSTRACT... Objectives: Self-directed learning is an active learning strategy in which students are accountable for their own learning by taking initiative. It has been supplemented with other instructional strategies like interactive lecturing, in order to enhance student's learning. The current study was carried out to determine the effect of supplementing self-directed learning with video clipping on students learning outcome. Study Design: Randomized Control study. Setting: Islamic International Medical College. Period: September 2016. Material \& Methods: This study was conducted among seventy six students of Islamic International Medical College. Students participated in a quiz competition whose syllabus of content and suggested reading materials were communicated to the students three week prior to the competition date. The registered students were than randomly divided into two Groups each comprising of 38 students. Self-directed learning of one group was supplemented with a video while the other group did not watch the video. Learning outcome of both groups was assessed by an MCQ exam. Results: The overall score of Self-directed learning group supplemented with a video was $65.17(7.68)$ while the score of self-directed learning group was 59.54 (8.54). A significant difference were found among the score of both groups $(p=.042)$. Conclusion: Self-directed learning when supplemented with the instructional strategy of video clipping leads to the improvement in the learning outcome of the students.
\end{abstract}

Key words: Instructional Strategy, Quiz Competition, Self-directed Learning, Video Clipping.

Article Citation: Sadiq N, Ali S. Enhancement of students learning outcome by supplementing Self-directed learning with video clipping. Professional Med J 2020; 27(7):1358-1362. DOI: 10.29309/TPMJ/2020.27.07.3661

\section{INTRODUCTION}

As a result of continued research, there is an enormous increase of knowledge in the field of medicine. Despite of the knowledge explosion majority of medical teachers still try to cover their contents through their boring, mind numbing, monotonous and passive lecture format which leads to the passive transmission of simple, recall knowledge to the students. ${ }^{1}$ Recipients of such lectures usually use rote memorization of factual information's just to pass their exams without any deep learning of knowledge and found to be poor in communication, critical thinking and problem solving skills. ${ }^{2,3}$ Incorporation of these skills does not depend upon what we teach but it depends upon how we teach i.e. on our instructional strategies. Medical education which was thought to be struck in time, space and content is now evolving and moving from traditional apprenticeship approach to the student centered approach containing multiple instructional strategies. ${ }^{4}$ These instructional strategies like selfdirected learning ${ }^{5}$, simulation based learning ${ }^{6}$, problem based learning ${ }^{7}$, role plays $^{8}$, mind mapping $^{9}$, peer assisted learning ${ }^{10}$, quizzes ${ }^{11}$ and educational games ${ }^{12}$ etc are opted in a way that they enhances students understanding of concepts and deeper learning and made them critical thinker and problem solvers. ${ }^{13}$

Self-directed learning (SDL) is an active learning strategy in which students are accountable for their own learning by taking initiative. ${ }^{14}$ SDL is among one of the emerging instructional strategies which has been proved valuable in enhancing deep learning, independent decision making and communication skills. ${ }^{15}$ Self-directed learning can be considered as effective as 
lectures. Various studies has been done in order to measure self-direction in Pakistan and worldwide. ${ }^{15-17}$ SDL has been supplemented with other instructional strategy like lecture in order to enhance student's learning but results showed that SDL when supplemented with lecture did not improve student's learning significantly as compared to students who only had an SDL session. ${ }^{17}$

One of the instructional strategies which create joy and love for learning is the use of videos which motivate students to participate in learning process and enhances their metacognitive skills. ${ }^{18}$ This instructional strategy allows the student to immerse in real life scenarios which are absent in the didactic instruction model of show and tell. ${ }^{19}$ Use of inexpensive pedagogically sound video clips can be used as an enjoyable medium of instruction for the new media engaged generation. ${ }^{20}$ various studies has been done in order to evaluate the effectiveness of videos in improving students learning outcome both nationally and internationally. Some studies concluded that supplementation of a teaching method with videos enhanced students learning outcome while other reported that supplementation doesn't result in significant improvement in the learning outcome. ${ }^{21-24}$

Previous studies have shown that supplementing SDL with lectures did not improves the learning outcome. Despite of the favorable reviews on enhancement of students learning by SDL alone, there is a lack of studies (EBME) examining whether supplementing SDL with video clipping will enhance students learning or not. So, the purpose of the current randomized trial is to determine whether supplementing SDL with video clipping will enhance students learning or not.

\section{MATERIAL \& METHODS}

This Randomized controlled trial was conducted at Islamic International Medical College on $16^{\text {th }}$ September 2016. Seventy Six students from $1^{\text {st }}$ year MBBS to $3^{\text {rd }}$ year MBBS participated in this study.

We conducted a quiz competition on the topic of Alzheimer's disease. Quiz competitions which acts a supplementary learning tool for students had already been held many time in our college but this was the first ever time we conducted a quiz competition on a very specific topic like Alzheimer's disease with an aim to increase its awareness among medical students. Detail of the course content and suggested reading material was communicated to the students three weeks prior to the competition date. Students were informed that their performance in the competition would not affect their course evaluation and every participant will get a certificate of participation in the quiz. Students were asked to get themselves registered before a closing date which was one week prior to the date of quiz competition. All the students from first year MBBS to third year MBBS who got registered before closing date were included in our study. As per our medical college curriculum the topic of Alzheimer's disease is not taught in detail to the first three years of MBBS so all off these students were supposed to have the same level of knowledge. Sitting arrangement was done to see the contribution from each class. Students were sited year wise in rows. Female students were asked to sit first followed by male students of that particular year in the same row. When all registered students got sited we briefed all the students about our study and we took their consent. We briefed them that even if they are not willing to take part in the study they are still eligible to take part in the quiz and they will receive the certificate of participation in any way. We briefed them that we will divide them into two groups one group will watch an video before the exam and the other group will also watch the same video but after the exam. Then we asked every second student from each row to leave the exam hall for 15 minutes. The remaining students watched a video. So we divided the students into two groups. Group A students that watched the video in addition to their self-study preparation for the quiz and Group B students that didn't watch the video and were purely the SDL group. It was a role play video of eight minutes duration showing the various aspects of the miserable life of an Alzheimer's disease patient. After that we took an exam of all the registered students. it was an MCQ exam comprising of Thirty eight MCQ's. Students 
were given forty minutes to attempt paper. Every $M C Q$ had the equal weightage and the paper had a mixed level of difficulty. No negative marking was done and none of the MCQ was directly related to the role play video.

We determined the MCQ scores of both groups. We compared the scores of SDL + video assisted learning group with that of only SDL group. Mean and standard deviation of both groups were computed and means were compared using Independent "t" test. A p value $<.05$ was considered significant. All statistics were done using the statistical software SPSS version 21.

\section{RESULTS}

A total number of Ninety Two students were registered for the quiz competition. Seventy Six students appeared in the competition. All of the appeared students gave their consent for the participation in the study. Video assisted learning group i.e. Group A comprised of 38 student (50\%) and SDL group i.e. Group B also comprised of 38 students (50\%). The mean score of Group A was $65.17 \pm 7.68$ while the mean score of Group B was $59.54+8.54$. SDL group supplemented with video clipping i.e. Group A performed significantly better than the SDL group i.e. Group B ( $p=.042)$

\section{DISCUSSION}

With the evolution of medical education, teacher centered instructional strategies has been shifted towards students centered instructional strategies which aims for the production of active learners, critical thinkers and problem solvers. Finding an instructional methodology which improves students learning is the topic of ongoing research. The present study was conducted in order to investigate whether supplementing self-directed learning with video clipping will enhance students learning or not.

A study done in Rawalpindi medical college, Pakistan concluded that Demonstration by dissection videos results in a small insignificant increase in anatomy term test scores. ${ }^{21}$ Another study done on the effectiveness of computer aided learning or e-learning by streaming video revealed that use of streaming videos of basic medical sciences for United States Medical Licensing Examination (USMLE) Step 1 doesn't statistically improves the test scores. ${ }^{22}$

\begin{tabular}{|c|c|c|}
\hline $\begin{array}{c}\text { Video Assisted self-directed } \\
\text { learning group (n=38) } \\
\text { Mean (SD) }\end{array}$ & $\begin{array}{c}\text { Self-directed learning } \\
\text { group (n=38) } \\
\text { Mean (SD) }\end{array}$ & t-test \\
\hline $65.17(7.68)$ & $59.54(8.54)$ & 2.10 \\
\hline Comparison of scores between video assisted self-directed learning group and self-directed learning group \\
\hline
\end{tabular}
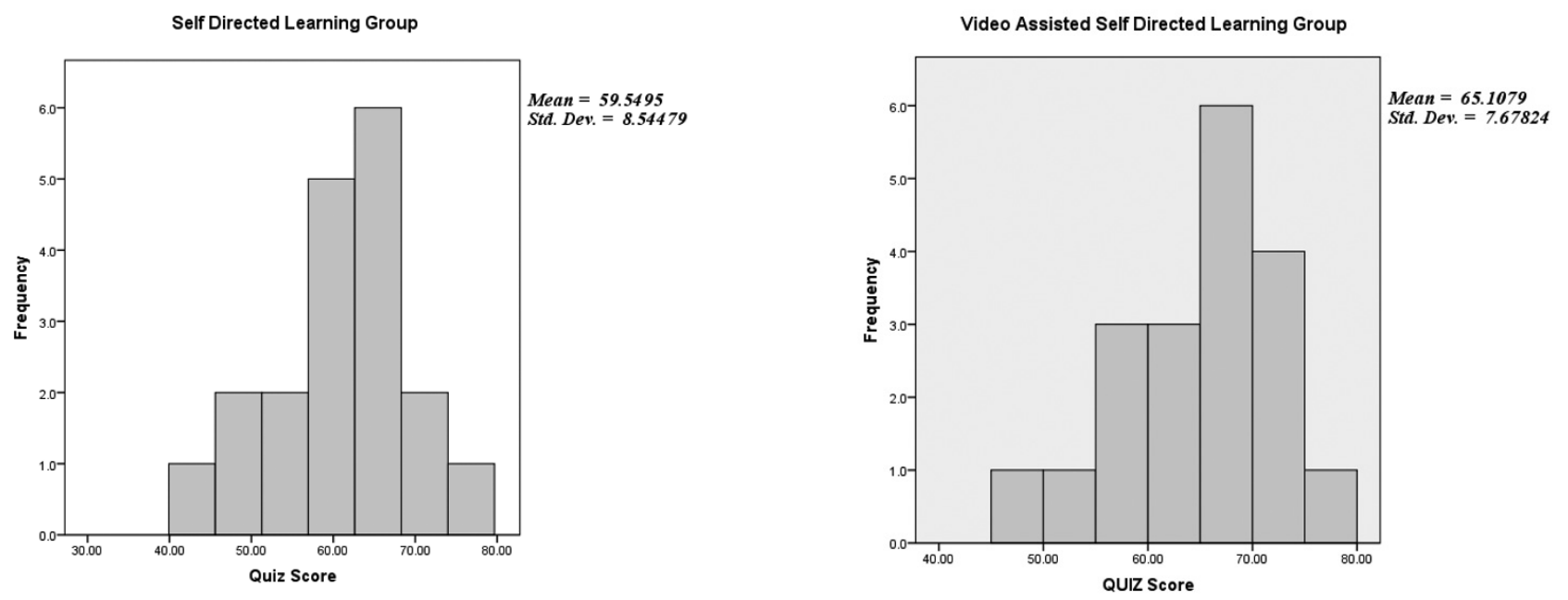
Stephanie $\mathrm{N}$ concluded that Video education is an efficient and convenient mode of teaching. Their study demonstrated that educating sterile surgical techniques to students by videos results in a better outcome as compare to teach by traditional skill demonstration. ${ }^{23}$ GJ Xeroulis also demonstrated in their study that video clipping as an instructional strategy increases the learning of surgery training residents. ${ }^{24}$ Our study also demonstrated that use of video clipping improves students learning outcome.

Lus $\mathrm{H}$. Montrezor conducted a study in which he used video along with other active instructional methodologies including puzzle, board game and debate designed for teaching a particular topic to a group of students and compared their learning out come with the group of students who were taught with traditional teaching and found that the group who watched video along with other active strategies performed significantly better than their respective control group. ${ }^{25}$ Our study also demonstrated that the videos with supplemented with self-directed learning strategy will improves students learning outcome.

Kirtana M pai et al conducted a study to explore the effectiveness of self-directed learning for teaching physiology they found that SDL can be considered as effective as lectures and supplementing SDL with lectures did not improves the learning outcome. ${ }^{17}$ In contrast to this study we supplemented SDL with video clipping instead of lectures and found that it improves the learning outcome of the students.

\section{CONCLUSION}

We have demonstrated that supplementing video clipping with the instructional strategy of self-directed learning significantly improves the learners outcome so video clipping should be added in the students curriculum along with the sessions of self-study.

Copyright $(11$ Oct, 2019.

\section{REFERENCES}

1. DiCarlo SE. Too much content, not enough thinking, and too little fun. Adv Physiol Educ. 2009: 33(4); 25764.
2. Michael J. In pursuit of meaningful learning. Adv Physiol Educ. 2001: 25(3); 145-58.

3. Michael JA. Mental models and meaningful learning. J Vet Med Educ. 2004: 31(1); 1-5.

4. Pulido M PA, Cravioto A, Pereda A, Rondón R, Pereira $G$. Changes, trends and challenges of medical education in Latin America. Med Teach. 2006: 28(1); 24-29.

5. Naveed T, Bhatti N. Reliability of self-directed learning aptitude survey tool. Pak Oral Dental J. 2017: 37(4); 601-03.

6. Mehmood MH, Siddiqi HS, Rehman R. Medical simulator, an innovative tool for experiential learning, application and reflection of knowledge. J Pak Med Assoc. 2018: 68(7); 1142-53.

7. Hussain H, Anwar N. Effects of problem based learning on students' critical thinking skills, attitudes towards learning and achievement. J Educ Res. 2017:20(2); 28-41.

8. Ahsen NF, Batul SA, Ahmed AN, Imam SZ, Iqbal H, Shamshair K, Ali H. Developing counseling skills through pre-recorded videos and role play: A preand post-intervention study in a Pakistani medical school. BMC Med Educ. 2010: 10(1); 7-10.

9. Ying $G$, Jianping $X$, Haiyun $L$, Xia L, Jianyu $Y$, Qun $X$, Jianyun $Y$. Using mind maps to improve medical student performance in a pharmacology course at Kunming Medical University. J Coll Physicians Surg Pak. 2017: 27(7); 404-8.

10. Shah I, Mahboob U, Shah S. Effectiveness of horizontal peer-assisted learning in physical examination performance. J Ayub Med Coll Abbottabad. 2017: 29(4); 559-65.

11. Rashid MN, Soomro AM, Abro AH, Noman SB. Medical students academic performance assessment in physiology courses using formative and summative quizzes at SMBB Medical College Karachi, Pakistan. J Appl Physiol. 2017: 2(1); 10-14.

12. Malhotra VM, Kabra PR, Malhotra R. Attitudes and practices of medical students regarding videogames: should community medicine educationists get serious about serious games. Int $\mathrm{J}$ Community Med Public Health. 2017: 4(3); 729-33.

13. Rashid T, Asghar HM. Technology use, self-directed learning, student engagement and academic performance: Examining the interrelations. Comput Human Behav. 2016: 63; 604-12. 
14. Knowles M. Self-directed learning: A guide for teachers and learners. Chicago, IL: Follett. 1975.

15. Peine A, Kabino K, Spreckelsen C. Self-directed learning can outperform direct instruction in the course of a modern German medical curriculumresults of a mixed methods trial. BMC Med Educ. 2016: 16(1); 1-5.

16. Mahmud W, Haroon M, Munir A, Hyder O. Self-directed learning and research attitudes among medical students. J Coll Physicians Surg Pak. 2014: 24(3); 17377.

17. Pai KM, Rao KR, Punja D, Kamath A. The effectiveness of self-directed learning (SDL) for teaching physiology to first-year medical students. Australas Med J. 2014: $7(11) ; 448-51$.

18. Senchina DS. Video laboratories for the teaching and learning of professional ethics in exercise physiology curricula. Adv Physiol Educ. 2011: 35(3); 264-69.

19. Gadbury-Amyot CC, Purk JH, Williams BJ, Van Ness CJ. Using tablet technology and instructional videos to enhance preclinical dental laboratory learning. J Dent Educ. 2014: 78(2); 250-58.
20. Van Vliet EA, Winnips JC, Brouwer N. Flipped-class pedagogy enhances student metacognition and collaborative-learning strategies in higher education but effect does not persist. CBE-LIFE SCI EDUC. 2015: 14(3); 26-29.

21. Mahmud W, Hyder O, Butt J, Aftab A. Dissection videos do not improve anatomy examination scores. Anat Sci Educ. 2011: 4(1); 16-21.

22. Bridge PD, Jackson M, Robinson L. The effectiveness of streaming video on medical student learning: A case study. J Med Educ. 2009: 14(1); 4506.

23. Pilieci SN, Salim SY, Heffernan DS, Itani KM, Khadaroo $R G$. A randomized controlled trial of video education versus skill demonstration: Which is more effective in teaching sterile surgical technique?. Surg Infect. 2018: 19(3); 303-12.

24. Xeroulis GJ, Park J, Moulton CA, Reznick RK, LeBlanc V, Dubrowski $A$. Teaching suturing and knot-tying skills to medical students: A randomized controlled study comparing computer-based video instruction and (concurrent and summary) expert feedback. Surgery. 2007: 141(4); 442-49.

25. Montrezor LH. Performance in physiology evaluation: Possible improvement by active learning strategies. Adv Physiol Educ. 2016: 40(4); 454-57.

\begin{tabular}{|c|c|c|c|}
\hline \multicolumn{4}{|c|}{ AUTHORSHIP AND CONTRIBUTION DECLARATION } \\
\hline Sr. \# & Author(s) Full Name & Contribution to the paper & Author(s) Signature \\
\hline 2 & $\begin{array}{l}\text { Noman Sadiq } \\
\text { Shazia Ali }\end{array}$ & $\begin{array}{l}\text { Literature review, Data } \\
\text { colletion, Write up. } \\
\text { Methodology, Write up, Overall } \\
\text { supervision. }\end{array}$ & 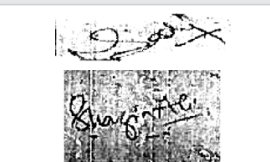 \\
\hline
\end{tabular}

